\title{
Non - Aligned Gendered Subjects in Jasmina Cibic's Tear Down and Rebuild
}

\author{
Mihaela Brebenel
}

\section{Transnational Networks}

The network historically produced by the Non - Aligned Movement (NAM) has been increasingly interrogated in the present by artistic and curatorial practices. Most recently, the Museum of Contemporary Art Metelkova in Ljubljana, Slovenia has dedicated a large exhibition to the inquiry of The Poetics of the NonAligned. ${ }^{1}$ In another large-scale curatorial and educational project titled The Travelling Communiqué, Kodwo Eshun and Doreen Mende argue that such interrogations can act as forms of resistance to a continuous 'bipolar historiography', maintained by sets of 'political discourses that continue to consign the Non - Aligned Movement to the margins of Cold War historiography.,2 To this historiography, the NAM arguably produced a 'third way', a transnational network, which could potentially teach us about a shared present.

As Francoise Verger writes, the different NAM members spread across Africa, Asia, and South America but shared the important objectives of ending imperialism, colonialism and racism, and of promoting peace and security. They thus shared an International decolonial project, the 'third way' mentioned above. In a contemporary global 'new era of land grabs, of vast spoliation of resources (...) when the Wretched of the Earth are now found in the North, South, East and West, these ideals still resonate. ${ }^{3}$

In order to ask what these resonances in the present may be, in this article I will focus on the contemporary work of Slovenian-born artist Jasmina Cibic. I ask what are the conditions and possibilities her works offer for engaging in this aforementioned resistance to a bipolar writing of histories. In a contemporary cartography, ex-Yugoslav and neighbouring nations, once a central part of NAM face the loss of transnational connections, increased misogyny, anti-immigration sentiment and increased racist and fascist political agendas.

How could a feminist critique of these networked histories look like? Artist Jasmina Cibic would say that such a project needs to start with looking at nation building processes. In her work, Cibic carries this task by investigating how the nation is continuously being built through architecture, art and other forms of cultural production. Her complex works make use of various media, in which a theme and strategies of dealing with it are explored, individual elements are picked up from their liminal positions and used as what she calls 'ornamental rashes' that take up spaces and reconfigure histories.

What is at stake in her artistic projects is not the link between architecture and ideology per se, as that is a fairly rehearsed investigation. Rather, her interest lies in two of modernity's interlinked issues around soft power and 'an escalating trend of channelling national culture for national promotion', issues that resurface in contemporary contexts, most obviously together with xenophobia and anti- 
LGBTQ rhetoric. Cibic's approach to this intertwined issue of soft power and cultural production is through attentive work with archives, where she engages with material from the visual arts, documentation of architectural plans, records of political protocols and encounters, travels and meetings between figures in art historical and political milieus. Cibic often re-stages aspects of a selected archive, giving precedence to or expanding one type of material or an element thereof and thus re-configuring orders and questioning the protocols and taxonomies, which set those materials in place. I argue that in her work, Cibic takes up three main strategies to enact a critique of the present, through the transnational network of the NAM. These strategies are fragmentation, circulation and mis-imagination of texts, images and artefacts.

\section{Non - Alignment and Networked Architecture}

In this article, I will focus on Spielraum (2015), a three-part project-exhibition: The Nation Loves It, Give Expression to Common Desires, and Tear Down and Rebuild. In a text on her artist website, Cibic considers its aim is to 'question the potential of instrumentalization of visual language, rhetoric and architecture in the construction of the State as spectacle throughout recent history and [to] investigate how art and architecture can serve as soft power strategies of every political order.' The title refers to Karl Kraus, a political satirical writer, and his essay Spielraum from 1912, in which he strongly opposes the use of decoration in language and architecture. The building, which hosted the first NAM conference, is the central piece of this project. Discrete sculptural and decorative elements are identified, isolated and re-circulated in installation, performance and moving image forms, towards the end outlined above.

For this project, Cibic worked with the former Palace of the Federation as archive material, with political speeches transcribed in historical documents and now found in constant circulation and fragmentation online, with materials from the former Yugoslav state archive, and with numerous photographs drawn from the archives of Josip Broz Tito's personal photographers.

This building was completed just in time to host the first NAM Conference in 1961. Tito called the conference because he was concerned about Cold War dynamics and the acceleration of the arms race. The meeting is retrospectively considered a central event in decolonial struggles, after the Bandung Conference of 1955. Tito's challenge with this building was an exercise in soft power through architecture: to create a space for the network to take up inside of the architectural projection of the multi-ethnic Yugoslav nation. A double projection occurred: the topography of the Non - Aligned network over and inside that of the nation-state and conversely, the imaginary connected to all the participating nation-states warped inside of a space meant to have room for all and accommodate the specificities of each one, in the spirit of Third World Internationalist solidarity. Accordingly, the challenge for the city of Belgrade was, as the artist notes on her website, to 're-define and re-design the environment for presentation to the foreign delegates attending the conference whilst simultaneously re-branding [itself] to its citizens.' 
The networked qualities of the NAM meet and morph between the historical and architectural in the anti-colonial nation-states (some newly independent), whilst the anti-imperial alliance to a Third World outside of Cold War binaries is entangled with architectural efforts across Eastern European and socialist states in Africa, South and East Asia and South America. The Palace is further interesting for its disavowal from Socialist Realist style and its strong influence continuing and interpreting a modernist tradition. In a more recent project, the Nada trilogy, Cibic traces a line of connections between the oldest of the networks tying history to modern architecture, the World Exhibitions started in 1851 at Crystal Palace, in London and further, to events like the Olympic Games and art biennials.

If we follow Cibic in this trajectory, we see the networked networks. By that, I mean the historical entanglements between an Internationalism of the World Exhibitions, with its undoubted centrality of the nation-state and its spectacle, in a critical position with the Internationalism projected by Tito from a multi-ethnic state towards decolonial struggles through a position of solidarity and further, into current curatorial interests around Internationalism. For instance, The Museum of Modern Art's recent large exhibition Toward a Concrete Utopia: Architecture in Yugoslavia, 1948 - 1980 frames Internationalism not through solidarity, but as an recuperated synchronicity of Eastern European spaces operating in a pre- or always-existing type of globalization, an a-temporal phenomenon not circumscribed to recent history.

In the next two sections of the article, I argue that Cibic's work shows how the networked spatiality of the NAM produced architectural forms like the Palace of the Federation, which, in their drive to strip down decoration have also further pushed gendered subjects to the liminal zones of the ornament. Cibic's Spielraum necessarily mis-imagines the NAM conference as a mediated event in a multitemporal network. In a critical manner, it blends this moment in history temporally and spatially with many other historical and contemporary networks, including networked culture as infrastructural, political and affective material space for producing more or less dubious, more or less ornamented iterations of networked Internationalism. ${ }^{5}$

\section{Gendered Subjects, Formations and Positions}

My interest lies in the moving image artworks that Cibic produces in Spielraum, specifically in Tear Down and Rebuild, which features four white women walking through the former Palace, in fine-cut contemporary minimal, professional outfits, whose colour tonality matches the bright interior murals. These bodies traverse spaces in the building whilst being in conversation with each other, a dialogue whose content, aim or ideology is not easily graspable. Each of their attitudes, however, is that of an expert, voicing out with apparent certainty what soon becomes clear are statements about the acts of building and tearing down, the role of architecture, possibly referring to the same building they are in. The scale of this building, with high ceilings and extravagant chandeliers matches that of its interior ornaments and of the large-scale mural paintings but contrasts the figures of these bodies, who appear small and are only amplified by their speeches. 
'One cannot help but wonder exactly who or what is on display in the films: Is it the buildings, the humans, or the abstract concepts? Or is it actually their ritualistic relationships?" asks Vladimir Kulic of Cibic's most recent work, the Nada trilogy. This question can be translated easily to Tear Down and Rebuild, as Cibic seems to carry it from project to project, revealing more ways in which subject positions are entangled with gender, nation building and Internationalism.

Tear Down and Rebuild populates the building with the presence these women, who deliver a collage of quotations about a number of what Cibic calls on her website 'ideologically contrived and historically charged buildings, monuments, walls etc. that were to be or were knocked down', as a nation builder, a conservationist, a pragmatist and an artist/architect. In the same website text, she continues to say that these women voice out their bodies by moving through space, forming a collection of 'found ready-mades spanning from language, architecture to historical events' and so, they become re-worked to be ambiguous enough to appear fitting in the architectural and historical context in which they are delivered.

Then, the building itself can be read as protagonist (a part of the urban plan for the New Belgrade, the physical embodiment of new ideas in post-war Yugoslavia) and a cultural material archive for understanding gendered subjectivity at that historical point in time. Further, the question is not whether the building or the protagonists are to be focused on, but to think subjectivity of the building and protagonists. The lived experience of gendered subjects in the Yugoslav nationstate is intersected with what can be found in forms of cultural productions, what they open up. If we return to Kulic's question: what is displayed is the historical topography of the NAM, the kinds of subjects it produced and how do we see that production today. It makes apparent how production of subjectivity in the NAM was gendered.

Cibic argues in the artist website presentation text that the 'all-female cast' with its four characters becomes 'an extension of the architecture and its fittings.' Read in this way, the relationship between the building and gender meets the inner projection of the multi-ethnic nation state. As Cibic points out, the interior decorations are made to mirror the six federal republics, together with their crafts, like woodwork, weaving or stone carving. Furthermore, also on the website this description appears:

The interior of the palace is densely populated with artworks and design. If one looks at the sculptures placed within it - one realizes they are all of female nudes, some of them in explicitly erotic poses or form. The parallel between the patriarchal protocol architecture representing a state and the absence of an active female voice, which is solely represented in a fixed, eroticized form, led me to delve further into the concept and representation of Mother Nation within the national discourse.

Her insertion of these figures thus becomes a strategy of response to how, not only are crafts like those decorating the interior of the building considered women's work, but also to how women are visualized as liminal and decorative figures, abstracted from their voices, bodies and their labour. Cibic continues this 
interest in the Nada trilogy, where female figures 'act as mouthpieces through which intricately researched tracts on the nature of power, aesthetics, and statecraft pour forth. They follow the dubious tradition of the allegorical female, descendants of stately mother nations. ${ }^{7}$ The socialist comrade who had to share the factory work, the labourer of most of the craft and other types of work, who had sole responsibility over all domestic work was the same comrade that had to meet all of the reproductive labour of the nation, Mother Nation. ${ }^{8}$

The decolonial intention of the Spielraum project is carried out at language and visual levels. In Tear Down and Rebuild, Cibic works with elaborate scripts, whilst architecture is the stage where, in her words, these 'dubious allegorical female characters' become the mouthpieces of these collaged positions.

She writes: 'A large part of my work surrounds fragmentation of political rhetoric. ${ }^{9}$ The discourses from Tear Down and Rebuild are constructed from fragments of texts from various political, artistic and journalistic writing, either by known authors or anonymously circulating on Internet blogs and other online platforms. They cover political speeches selected from those of Margaret Thatcher at the demolition of public buildings, to Regan's speech on the Berlin Wall, to Prince Charles's 1984 address at the Royal Institute for British Architects; debates and proclamations on iconoclasm of architecture and art, central here being texts on the architectural form by Loos; and statements on monument demolition and redesign, such as the alleged online declarations made by Islamic State of Iraq and the Levant (ISIS/ISIL) around the destruction of Syria's Palmyra ruins. The accessibility and confusing circulation of these texts online is rendered as coherent speeches using a technique similar to remixing.

In terms of the visual fragmentation, Cibic has worked closely not just with the building itself, but also with its plans and designs. When it comes to the works in Spielraum as a whole project, her stake extends from the building to the city's built environment and she states in the website description of the work that the goal was to 're-configure the visual elements contained in the sketches, plans and drawings for the city with its unique pavilions, monuments and decorative additions intended to reimagine the image of the city.' The modernist claim to anti-decoration is taken up and elements of the material, which surface in the research process are expanded upon and become what she calls 'a specific kind of ornamental rash that spreads across my installations as an enhancer of the emblematic of the theoretical horror vacui of empty walls, ${ }^{10}$. To the previous aspect of liminality in terms of how gendered subjects were produced by the interior of the building, the issue of virality is taken up with this idea of the ornamental rash. An infectious making visible of the discourses and the ideologies it rests upon, that is based on the selection of a limited number of formal elements and their repetitive and patterned circulation, exposing singular events, subjects or fictions of the past or of the current moment.

After the NAM conference, the role and function of the building has changed several times and now, Cibic argues in her website description of the work, could at best be a depository of exoticised 'sculptural forms and images read as political propaganda' in Western exhibitions on Yugoslavian architecture, a form of circulation of this architecture after the fall or what some call it 'vanishing act of 
socialism,' with multiple re-appearances. ${ }^{11}$ With this exoticism, contemporary art world and exhibition making as a structure of circulation and visibility renders opaque the discussions around solidarity, anti-fascist and anti-racist struggle into form. Cibic only apparently reduces these complex issues to a few singular forms that she repeats and then, like metadata, a number of relational and networked connections start appearing, as historical notes and fictional constructions.

In fact, a central concern for her work is 'whether it is possible at all to decolonize the art sector of its geopolitical-exotic pull ${ }^{12}$ when it comes to different ideological spaces, in particular how this exoticism manifests for ex-Yugoslavia in the art market, in recurrent ways since the 1990s. Tear Down and Rebuild, Cibic proposes in the website description of the work, 'an examination not only of the methods of the self-presentation of the state, but also the way in which the whole of the state became a sort of reception committee for the new "third way", the Non - Aligned Bloc.' As such, it functions as an attempt to perform a decolonizing strategy of circulating the remixed, fictional and liminal spaces and characters in a historical building, making visible how it exerts the above geopolitical exotic pull.

\section{Tearing Down and Rebuilding}

I have outlined how Cibic takes up three main processes in her work as strategies towards a critical reading of NAM architecture and histories in the present: fragmentation, circulation and mis-imagination. Having discussed the first two strategies previously, in this section I will focus on the latter.

What does tearing down refer to in the title of the work? Cibic says that her intention is to produce an act of what she calls mis-imagination. She thus imagines, through the speeches collated, that the building is about to be torn down. However, the building in question is not the former Palace of the Federation, the architectural site where moving images are produced, which opens up so much of what I have covered in aesthetic and political terms so far. The viewers of Tear Down and Rebuild become witnesses to how a fictitious building is constructed and to how the decision to demolish it grows from the conversation of these four allegorical figures. The construction starts from the site, a extraneous space in a dual network of Cold War power, whose form and political role was meant to re-organize world politics. The building that is formed in the dialogues is as much fictitious as the Palace itself is or has been in its historical role: they are both fictitious in the sense that their role and importance is constructed through language and performance.

I will advance here that this technique is chosen because it is pertinent for engaging with contemporaneity or the contemporary condition, as it requires reckoning with the losses, fictions, and horizons produced or dismantled by a series of historical events. Peter Osborne suggests that two main losses marked the time-space since the reductively labelled the fall, or the moment after 1989: " "communism" as the horizon of historical communism (...) and "revolution", as a horizon of expectation of revolution has been dissolving in advanced capitalist and colonial societies. ${ }^{, 13}$ The loss of these horizons took place concomitantly with the restitution of capitalism as a 'horizon of endless accumulation (...), politically 
coded in economic terms as the progressive freedom of ever-greater consumption ${ }^{14}$. Thus, the work to be done becomes to rethink, in this case with the help of work by contemporary artists and theorists, the notion of horizon and that of futurity, as possible critical instruments for decolonial work.

However, to do so insisting on the language of loss could be problematic. Certainly, the loss of horizons does not need to mean the loss of a common ground. It could at least open up the possibility to create forms of co-habitation of the losses, imaginations and mis-imaginations.

What is more, not just notions of loss and horizon require critical reassessment, but also, futurity and contemporaneity are problematic. According to Osborne, contemporaneity is 'problematic, in a more fundamental sense, because of its attribution of unity to the temporal mode of the present, however hypothetical, as such. ${ }^{15}$ Nevertheless, as a generative concept, contemporaneity brings forth two other concepts: productive imagination and operative fictions. For Osborne, all constructions of the contemporary are fictions. Fiction has a role to play in the contemporary because, in a generative understanding, it can be used to challenge the 'real', which is not a fixed form in the social, aesthetic or political world, but a space, which presents itself always with the possibilities of being fictionalized. I am interested in what happens when moving images become used in the creation of these operative fictions and, in the case of Cibic's work, to trigger acts of productive mis-imagination.

Osborne points out that the contemporary itself is a fiction. More specifically, constructions in the contemporary are fictional because of the way in which the contemporary promises a shared time. The contemporary as a fiction also extends to the fact that 'increasingly, the fiction of the contemporary is primarily a global or a planetary fiction. ${ }^{16}$ Is it possible to perform a reconsideration of the notion of contemporaneity outside of a historical periodization in stages, but as an operative fiction, which can inform on subjectivity, experience, and possibilities of common or collective action? The construction of the Yugoslav nation started as necessary anti-fascist liberation movement having the People's Liberation Struggle at its centre. But, as Cibic's project shows, it also ended in a state project that used women's body as decoration and her labour as form, and vice-versa. What futures were thus imagined in that nation building and in that moment in 1961? What would mean to think not just in terms of buildings, monuments and cities but also in terms of entire futures?

As much as the NAM was concerned with solidarity and transnational support, multiple structures of violence have played their role in the network, as much between nation-states, as within them. The possibility of a 'third way' that the NAM offered was torn down with the fall of several horizons. Interrogating these fallen horizons and torn down possibilities means also to rebuild them in the contemporary, where and when they seem to open up resonances and promises. In turn, this means to interrogate the very logic of debt and promise. 'What is a debt, anyway? A debt is just the perversion of a promise. It is a promise corrupted by both math and violence', David Graeber offers. ${ }^{17}$ Building on debt, without having taken responsibility over the past but promising to create anew is what Cibic picks up in her work. When any debt is left unpaid, then a contract has been 
broken. Tear Down and Rebuild is concerned with parsing out debt and promise in this historical transnational network, from the contemporary. Cibic's work shows the inseparability of tearing down from rebuilding, debt from promise, and body from labour in constructing an imagination of Internationalist solidarity in the historical Non-Aligned network as much as in the contemporary moment.

\section{Notes}

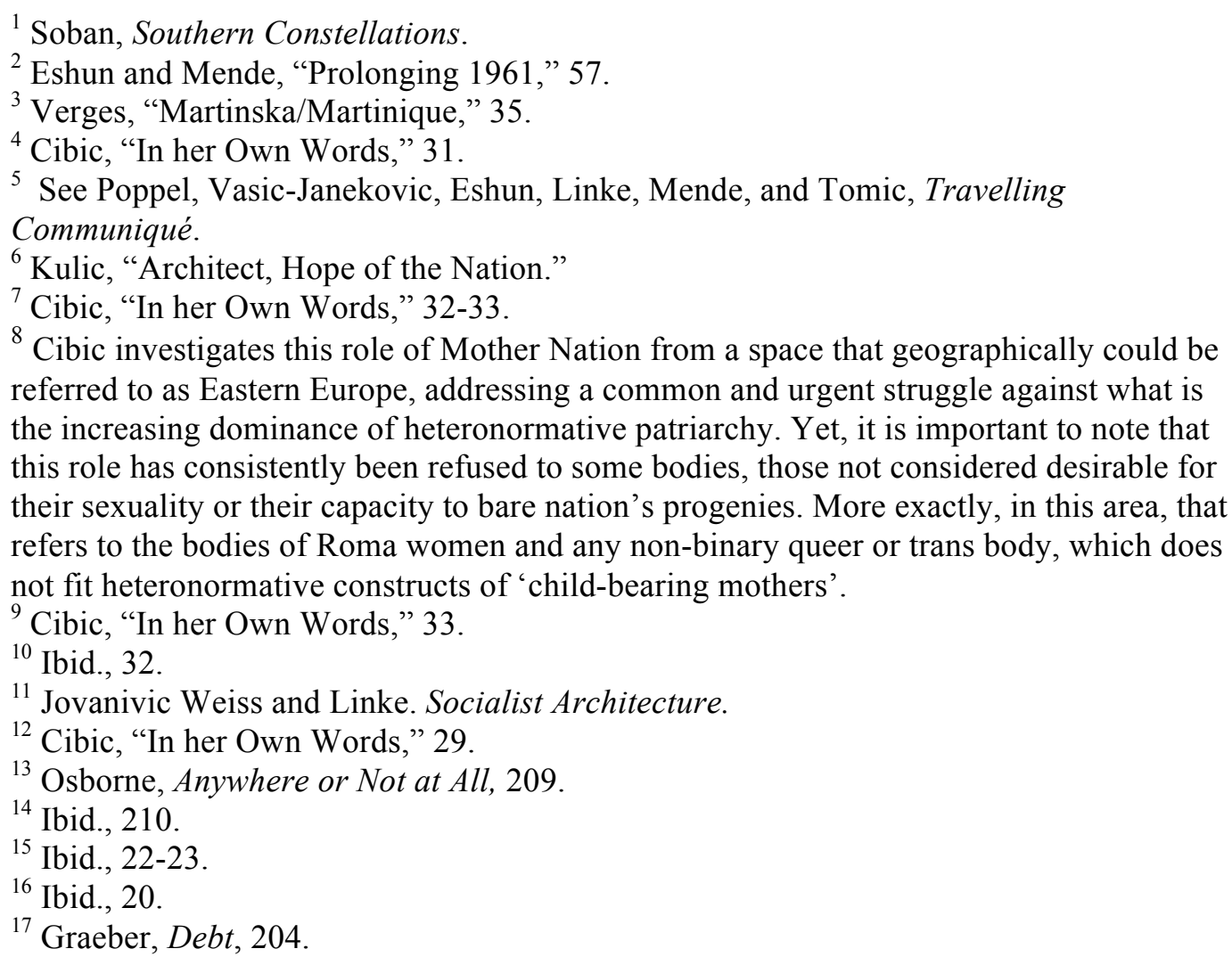

\section{Bibliography}

Cibic, Jasmina. "In her Own Words: Jasmina Cibic in Conversation with Katia Baudin and Constanze Zawadsky." In Nada, edited by Katia Baudin, 25-40. Berlin: Kerber Verlag, 2018.

Eshun, Kodwo and Mende, Doreen "Prolonging 1961: A Communique Sent Into the Future." In Travelling Communiqué: Studying Practices of Decolonial Thinking through the Presidential Photo Archive of Josip Broz Tito at the Museum of Yugoslav History, edited by Sarah Poppel, Vanessa VasicJanekovic, Kodwo Eshun, Armin Linke, Doreen Mende, and Milica Tomic, 5173. Leipzig: Spector Books. 2017.

Graeber, David. Debt: The First 5,000 Years, Brooklyn: Melville House, 2014.

Jovanivic Weiss, Srdjan and Linke, Armin. Socialist Architecture. The Reappearing Act, Berlin: The Green Box, 2017. 
Kulic, Vladimir. "Architect, Hope of the Nation In Nada, edited by Katia Baudin, 59-68. Berlin: Kerber Verlag, 2018.

Osborne, Peter. Anywhere or Not at All: Philosophy of Contemporary Art, London, New York: Verso, 2013.

Soban, Tamara, ed. Southern Constellations: The Poetics of the Non-Aligned. Ljubljana: Moderna Galerija. 2019.

Verges, Francoise, "Martinska/Martinique. Aime Cesaire Return to My Native Land." In Travelling Communiqué: Studying Practices of Decolonial Thinking through the Presidential Photo Archive of Josip Broz Tito at the Museum of Yugoslav History, edited by Sarah Poppel, Vanessa Vasic-Janekovic, Kodwo Eshun, Armin Linke, Doreen Mende, and Milica Tomic, 25-37. Leipzig: Spector Books. 2017.

Dr. Mihaela Brebenel is a screen and visual studies researcher and curator interested in feminist and queer practices, and in the aesthetics and politics of screen (and other) technologies. Brebenel is Lecturer in Digital Cultures at Winchester School of Art, where they are part of the Archaeologies of Media and Technology and Intersectionalities: Politics, Identities, Cultures research groups. Email:m.brebenel@soton.ac.uk. 